\title{
Pragmatics of hybrid approach DEAVIKOR to assess international airports of Iran
}

\author{
Amin Foroughi ${ }^{1 \star}$, M.H.Tahari Mehrjardi ${ }^{2}$, Hamid Babaei meybodi ${ }^{2}$ and M.J. Esfahani ${ }^{1}$ \\ ${ }^{1}$ Young Researchers Club, Naragh Branch, Islamic Azad University, Naragh, Iran \\ ${ }^{2}$ Department of Economics, Management and Accounting, University of Yazd \\ amin.foroghi@gmail.com
}

\begin{abstract}
The purpose of this paper is to present a hybrid approach from techniques of data envelopment analysis (DEA) and VIKOR for analyzing airport performance. Techniques of DEA has been used along with inputs such as number of workers, terminal space, length of the band and outputs such as number of the flights, number of the transported passengers and amount of the luggage. The efficiency of the airports has been accounted by 49 different inputs and outputs synthesis by using DEA. So that by using efficiency points of the airports in different synthetic inputs and outputs, a decision matrix was made in that the rows of this matrix were airports and the columns were the efficiency marks of different models, and at the end VIKOR technique was used for ranking the airports. The results of the final ranking showed Zahedan airport in the first place and Isfahan airport in the last place.
\end{abstract}

Keywords: Data envelopment analysis, Vikor, International airports.

\section{Introduction}

Nowadays, the efficiency and usefulness of air transport industry is considered beyond offering its transporting services, as air transportation has influenced economic life, social and cultural views and is effecting on forming historical and political condition of societies. This industry offers new solutions for job creation and businesses; on the other hand it prepares good opportunities for permanent transitions of information and facilitates the familiarity of the owners of different cultures and traditions. One of the necessities to improve in this area is permanent assess of their efficiency by using proper tools (Yang, 2010). In current economy, assessing efficiency of the airports seems to be necessary because of increasing strategic importance in passengers and cargo transportations (Barros et al., 2008). In addition, as per the new principles in Iran, the government encourages all the industries to increase (their own) efficiency. These principles are to increase the 8 percent improvement of gross domestic production in a year, so that third of this improvement shall be borne by increasing efficiency. To this effect, increasing the effectiveness of industry of country's airport is a practical way to increase efficiency (Roghanian et al., 2010).

The purpose of this research is to offer a model to assess international airports of the country. Data envelope analyzing method that is used for counting effectiveness of the organization units and separates efficient organization units from inefficient ones and studies and recognizes the reasons for inefficiencies of the inefficient units (Ahmadreza, mehregan,2007) is the base of our modeling research. The weakness of this method is that the number of assessed units is related to the strategy inputs and outputs. So the more the number of variables, the less are the power of distinguishing the units under assess by the model (Bal et al., 2010). So in this condition the number of variables of the model should decrease. In this research has been tried to offer a synthetic approach of data envelopment analysis, shanon anthropy and tapsis remove this weakness. This research is new and novel regarding the fact that this kind of assessing for the first time for country airport and especially about international airport has been done.

\section{Data Envelopment analysis}

Data envelopment analysis (DEA) is one of the nonparametric techniques that is widely used in different researches (Sohn et al., 2004; Seol et al., 2007). The purpose of this technique is to reach a relative effectiveness of the same decision making units which have some similar inputs and outputs (Samoilenko et al., 2008). Although each day the number of cover assessing of the data model increases and each one looks especial, but base of all of them are a number of basic models that the founders of this method have designed. Of these models we can point to Charns, Cooper and Roodez (1978) as CCR assumption of fixed efficiency with scale (CRS) was used in the analysis (Charnes et al., 1978) and also another model, offered by <Banker, Charns and Cooper> is BBC that with the assumption of variable efficiency in relation with scale (VRS) has been designed (Banker et al., 1984). From one point of view DEA models are divided to two groups with input essence and output essence. Purpose of the models with input essence, offering the improvement way by decreasing the inputs, and purpose of the models with output essence is to design the improvement way is by increasing the outputs (Ahmadreza \& mehregan, 2007). Data envelopment analysis divides the units under consideration into two groups of efficient and non-efficient. The efficient units can be ranked based on their non-efficiency grade but this cannot be possible for the non-efficient units. Because their efficient grade is equal to one. For ranking these units methods like cross efficiency and method of
Research article

CIndian Society for Education and Environment (iSee)
"Air port ranking"

http://www.indjst.org
Amin Foroughi et al. Indian J.Sci.Technol. 
Anderson-Peterson (AP) is available (Andersen et al., 1993). In this research input base BCC model has been used as the base instead of other models of cover assessing of the data. The reason for selecting input base is lack of enough control outputs of the country airports. So for analyzing them the input based models are more suitable. From one side the amount of efficiency in relation to the scale also has been considered regarding probable changes. BCC input base model is as follows (Ahmadreza \& mehregan, 2007).

$$
\begin{aligned}
& \operatorname{Max} Z_{0}=\sum_{r=1}^{s} u_{r} y_{r 0}+w \\
& \text { St: } \quad \sum_{\mathrm{i}=1}^{\mathrm{m}} \mathrm{v}_{\mathrm{i}} \mathrm{x}_{\mathrm{i} 0}=1 \\
& \sum_{r=1}^{s} u_{r} y_{r j}-\sum_{j=1}^{m} v_{i} x_{j j}+w \leq 0 \\
& x_{i j} \text { : input ith for } \mathrm{jth} \text { airport } \mathrm{j} ; \mathrm{i}=1,2, \ldots, \mathrm{m} \\
& y_{r j}: \text { Output rth for jth airport; } r=1,2, \ldots \text {, } \\
& v_{i} \text { : Weight of input ith } \\
& u_{r} \text { : Weight of output rth } \\
& \mathrm{u}_{r}, \mathrm{v}_{1} \geq 0 \mathrm{~W} \text { : Type of return to scale| }
\end{aligned}
$$

\section{IKOR}

Decision making multi criterion models are of decision making models that in late two decades have been more welcome. These techniques and models in complex decision makings when different and sometimes opposite criterion exist are widely used. The high power of these techniques to decrease complexity of decision making, using at the same time of qualitative and quantitative criterion and giving an structured framework to the problems for decision making and at last their easy use has made decision makers to handle them as a means in different fields. This technique formulates the problems for decision in the form of a decision matrix and does the necessary assessments.

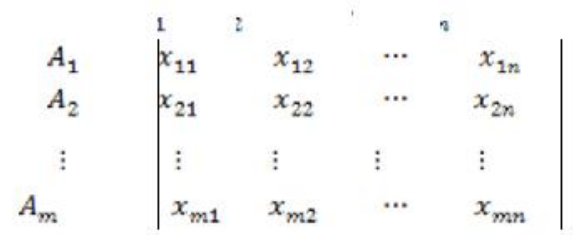

In this matrix $A_{i}$ represents index $j$-th and $X_{j}$ represents index value $j$-th for the choice 1-th. The methods of multi index decisionmaking are different and each one has its own characteristics and especial application condition. One of the most important methods that by now have been used in decision-making is VIKOR technique (Andersen \& Petersen,1993; Charnes et al., 1978).

The vikor method contains the following steps:

1) Dis scaling of decision matrix with the use of following relation:

$$
f_{i j}=\frac{x_{i j}}{\sqrt{\sum_{l=1}^{m} x_{i j}^{2}}}
$$

2) Determining ideal positive solution $\left(\mathrm{A}^{+}\right)$and ideal negative solution $\left(A^{-}\right)$by use of following relations:

$$
\begin{aligned}
& A^{+}=\left\{\left(\max _{i j} \mid j \in J\right) \text { or }\left(\min f_{i j} \mid j \in j\right) \mid i=1,2, \ldots, m\right\} \\
& =\left\{f_{1}^{+}, f_{2}^{+}, \ldots, f_{j}^{+}, \ldots, f_{n}^{+}\right\} \\
& \begin{aligned}
A^{-}=\left\{\left(\min _{i j} \mid j \in J\right) \text { or }\left(\max f_{i j} \mid j \in j\right) \mid i=1,2, \ldots, m\right\} \\
=\left\{f_{1}^{-}, f_{2}^{-}, \ldots, f_{j}^{-}, \ldots, f_{n}^{-}\right\}
\end{aligned}
\end{aligned}
$$

3) Accounting desirable value $\left(S_{t}\right)$ and undesirable value $\left(R_{t}\right)$ for each choice by use of the following relations:

$$
\begin{aligned}
& s_{i}=\sum_{j=1}^{n} w_{j}\left(f_{j}^{+}-f_{i j}\right) /\left(f_{j}^{+}-f_{j}^{-}\right) \\
& R_{i}=\operatorname{Max} x_{J}\left[w_{j}\left(f_{j}^{+}-f_{i j}\right) /\left(f_{j}^{+}-f_{j}^{-}\right)\right]
\end{aligned}
$$

That in above relations is accounted as desirable andundesirablevalues of each choice and $W_{j}$ as the weight of each criterion. Weight of the criteria usually is gained from different methods of giving weight like Anthropy method and AHP and... that in this research as mentioned before for calculating the weights of the indexes Anthropic method has been used.

4) Calculating VIKOR index by use of the following relation:

$Q_{i}=v\left[\frac{S_{i}-S^{+}}{S^{-}-S^{+}}\right]+(1-v)\left[\frac{R_{i}-R^{+}}{R^{-}-R^{+}}\right]$

That in above relation $Q_{i}$ as the VIKOR index value for the choice i-th

$\mathrm{R}^{+}=\operatorname{MinR}_{\mathrm{t}} ; \mathrm{R}^{-}=\operatorname{MaxR}_{\mathrm{t}}$;

$\mathrm{S}^{-}=\operatorname{MaxS}_{\mathrm{t}} ; \mathrm{S}^{+}=$MinS $_{\mathrm{t}}$

And $V$ as the weight of maximum group desirability that is usually considered as $0 / 5$.

5) Ranking the choices: Vikor technique allotted for the choice that has the least weight, the best choice from the point of technique is VIKOR.

\section{International airports of Iran}

The airports of the country are divided to three groups of internal airports, air frontier airports and external airports. From among 54 airports under the control of the company of country's airports about 8 airports have the capabilities to do external flights. These airports are Mehr abad, Shiraz, Isfahan, Mashad, Bandar Abbas, Imam Khomeini (God bless his soul), Zahedan and Tabriz 
airport. Mehr abad international airport as the most famous and oldest airport of the country founded at 1938 and after establishing the pilot's club with 20 airplanes.

This airport has the capacity to admit 12 million passengers every year and as before is the main center of aviation airport services in country. Zahedan airport that is used from the year 1967 has flight to abroad countries from the year 1995.This airport withTwo external and internal terminals have the capacity to transport 1/5 million passengers each year. The first airport of Bandar Abbas from about 1950 to 1967 was in a place called Band-e-Gonaran in 25 kilometers of today's road of Bandar Abbas -Sirjan (BaBa Gholam area) that from 1967 to 1970 Bandar Abbas airport changed its location and relocated where now a part of Shahid Mohammadi hospital is there and rebuilding the new airport (today's airport) began at the same time. This airport with two internal terminals and one terminal for external flights and to bands has the capacity to admit more than 847 thousand passengers.

For the first time in 1947 an office called wireless aviation began to work in Tabriz, in the year 1949 wireless aviation changed its name to aviation station and a dusty flight band and current place of the airport began to work till in the year 1950 by installing aero navigation instruments in the airport area the aviation station changed its name to Tabriz airport and in the year 1958 the operations to build control tower began and in the year 1959 came to use.

Today this airport has 100 internal flights and 20 external flights each week. Isfahan airport is one of the oldest airports in the country that was located at Soffeh area in Isfahan and because of some reasons at that time the old airport was given to Sepah aviation force and the new airport established in the north east of Isfahan in a place about a thousand hectares at 1982 and officially in an operative form entered into aviation possibilities. Shahid Beheshti, the international airport of Isfahan with two flight bands, one internal terminal and one external terminal are a place to admit all kinds of passenger planes.

Imam Khomeini (God bless his soul) international airport to meet the passenger and cargo needs of internal and external flights, and accepting transit flights to reach a place where Iran as the main center in international flights of the region and a passing canal in the route of Europe and Asia and at the same time foreign exchange incomes in result and benefiting more of tourism industry has been in the center of special attention.

Passenger's terminal has the capacity to admit $4 / 5$ to 5 millioninternational passengers. The international airport of Mashhad located in south east of the city of Mashhad and was established in the year 1955, which the airport's basic terminal was used for internal and external flights in the year 1967. Capacity of this airport is around three million and fife hundred internal passengers and next to 730 thousand external passengers and every year accepts more than 27 thousand pilgrims of Haj Tamato and 208 thousand pilgrims of Haj Omreh (www.airport.ir).

Research history

Although in the area of applying the technique of data envelopment analysis for analyzing airports of Iran a few researches are available, but in other countries there are a lot of researches. Some of these studies in the area of assessing internal airports of a country and some other are related to assessing the airports of some countries. Documents show that the inputs and outputs used by the researchers are different but the common outputs used in most researches is related to the number of passengers and the amount of carried cargo. Some of the late researches have considered unwanted outputs like delayed time and plane's noise (Pathomsiri et al., 2008) and (Yu et al., 2008).

In the case of applying inputs in these researches there are two different approaches. Some of these researches have considered inputs like finance, work force, and costs of operations and some other researchers have considered physical structure of the airport like band, atmosphere of the terminal, entrance by road for assessing. With regard to this fact that any kind of agreement does not exist in the case of the kind of efficiency to the scale, some of these researches have considered the theory of fixed efficiency to the scale and some other the theory of variable efficiency in relation with the scale for assessing. Also these researches have used of two pivotal input oriented and pivotal output oriented for research models. A summary of these researches is in Table 1.

\section{Research method}

The current research is practical, from the point of view of time single point and from the point of view of method of practice is descriptive- mathematical. This research follows to offer a model to assess international airports with the approach of data envelopment analysis. Although there are more than 54 airports in the country but most of them are almost inactive and a few regular flights is done. So in this research the international airports of the country for the wide activity in airport industry have been chosen for assessment. With the help of the basics and offered definitions in the area of literature the research about technique of data envelopment analysis and also the studies underdone for assessing the activity of airports with this technique and after that with the use of interview with the elite (Khobregan) the elements effective in assessing become known. With the use of these indexes, the inputs that essentially showed the sources applied and the outputs, which show the level of activity of decision units, were determined. Table 2 shows inputs and outputs of the chosen airports and their information that is related to the activity of the year 2008. In this research with the use of different combinations of inputs and outputs efficiency of
Research article

CIndian Society for Education and Environment (iSee)
"Air port ranking"

http://www.indjst.org
Amin Foroughi et al. Indian J.Sci.Technol. 
Table 1. Researches about efficiency of airports in the world

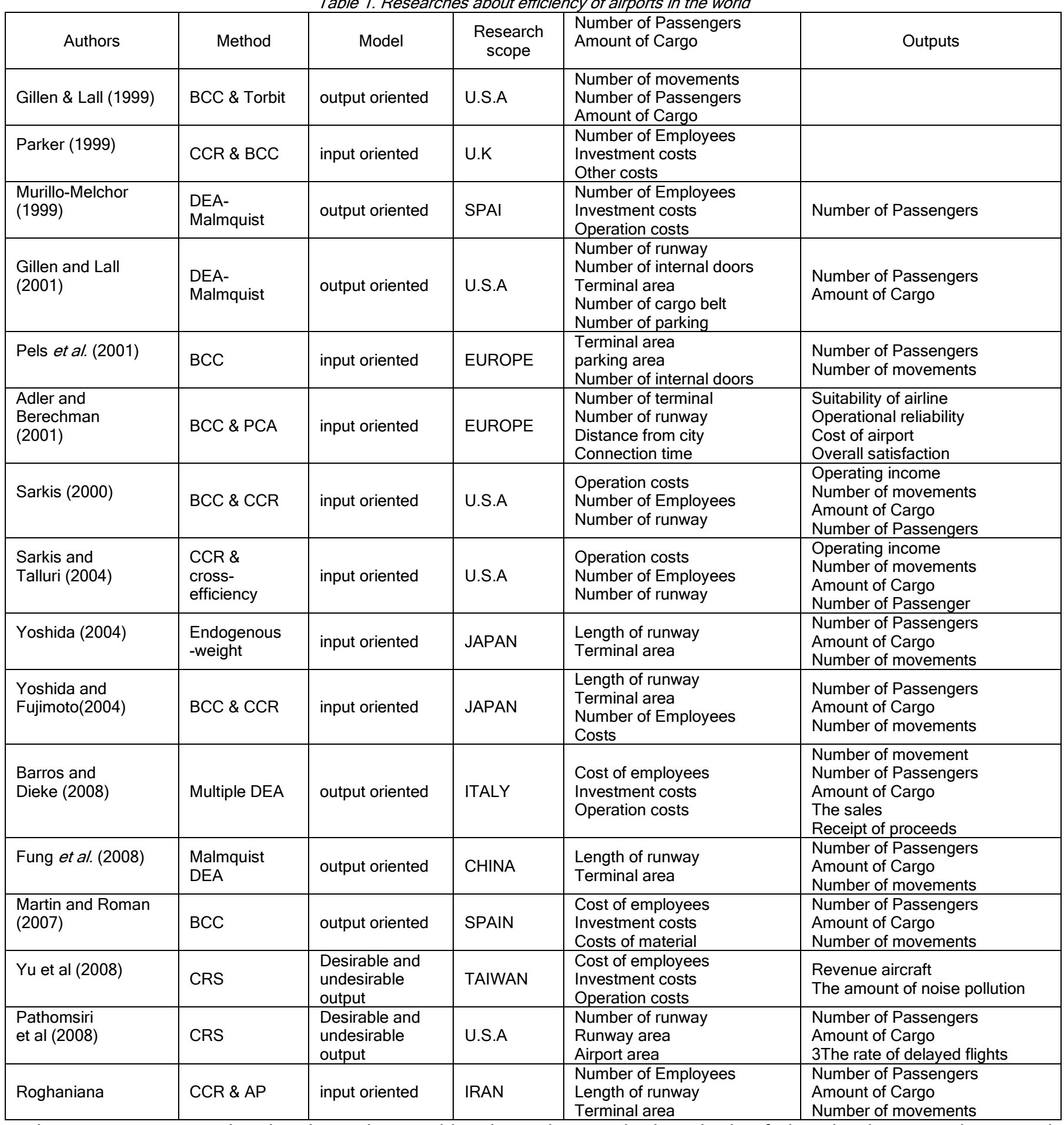

the airports was measured and at the end to combine the results of different models the VIKOR technique was used and a complete ranking of the country's airports has been gathered.

\section{Assessing efficiency of the airports with combinations of} different indexes

In this research different combination of inputs and outputs is used for DEA technique. For instance one of the standard methods of choosing inputs and outputs in this research is to consider every three inputs and outputs for the model that we in this study show it with $A B C 123$ symbol. with the existence of variable input and three variable output, totally for each airport 49 model of combination of inputs and outputs has been designed and with regard to the existence of 8 airports as a whole about $\left(49^{\star} 8\right)=392$ model was designed and solved.
Research article

COIndian Society for Education and Environment (iSee)
Amin Foroughi et al. Indian J.Sci.Technol. 
Table 2. Inputs and Outputs of international airports

\begin{tabular}{|c|c|c|c|c|c|c|}
\hline \multicolumn{3}{|c|}{ Outputs } & \multicolumn{3}{|c|}{ Inputs } & \multirow[b]{2}{*}{$\begin{array}{l}\frac{t}{0} \\
\frac{2}{2} \\
\frac{2}{2}\end{array}$} \\
\hline 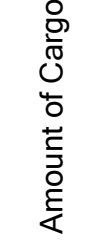 & 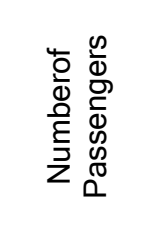 & 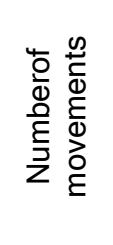 & 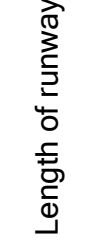 & 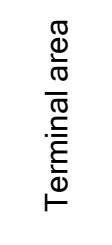 & 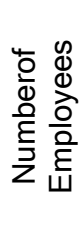 & \\
\hline 3 & 2 & 1 & C & B & A & \\
\hline 92426 & 3939532 & 27392 & 4198 & 78000 & 560 & imam \\
\hline 81649 & 10846868 & 89514 & 8150 & 76370 & 573 & $\begin{array}{l}\text { Mehr } \\
\text { abad }\end{array}$ \\
\hline 23839 & 4109982 & 29585 & 7736 & 38778 & 218 & Mashad \\
\hline 7232 & 853580 & 6747 & 7171 & 11800 & 166 & Tabriz \\
\hline 15988 & 1525183 & 13262 & 8794 & 21050 & 215 & Isfahan \\
\hline 5664 & 826158 & 7088 & 7133 & 9300 & 146 & $\begin{array}{c}\text { Bandar } \\
\text { abas }\end{array}$ \\
\hline 22177 & 1902506 & 19438 & 8601 & 23000 & 197 & Shiraz \\
\hline 4886 & 348196 & 2722 & 4250 & 6800 & 109 & Zahedan \\
\hline
\end{tabular}

Serano and coworkers (2005) declare two reasons for considering different combinations of inputs and outputs in DEA models:

First that all the combinations of inputs and outputs are equally analyzed. Second is that with regard to this fact that the efficiency mark of each decision unit in DEA models depends on the way of choosing inputs and outputs. So after solving all the models one can analyze the good points and weak points of the units under inputs and outputs (Bruce Ho et al., 2009). The result related to efficiency of international airports of the country under the different models is shown in Table 3.

As it is obvious in the above table the marks of the efficiencies of the airports is in an interval between zero and one. The achieved results of the complete model ABC123 that considers all the inputs and outputs for the model shows that from among 8 airports under consideration about 6 airports named Imam, Mehr Abad, Mashhad, Bandar Abbas, Shiraz and Zahedan has achieved at most 100 percent of efficiency by the mentioned model and this shows that the complete model of $A B C 123$ has the low power of distinguishing in assessing the airports. By comparing efficiency of the airports under different combinations we can see that some of the airports under assessing different models gain lower grades of efficiency. For example Imam airport

Table 3. efficiency of international airports of the country under the different models

\begin{tabular}{|c|c|c|c|c|}
\hline \multicolumn{5}{|c|}{ СIIETEIIL IIUCETS } \\
\hline Rank & $Q_{i}$ & $R_{i}$ & $S_{i}$ & Airport \\
\hline 4 & 0.606081 & 9 & 1 & imam \\
\hline 2 & 0.496396 & 2.9584 & 0.9273 & Mehr abad \\
\hline 6 & 0.708262 & 17.5144 & 1 & Mashad \\
\hline 7 & 0.925793 & 35.6405 & 1 & Tabriz \\
\hline 8 & 1 & 41.8239 & 1 & Isfahan \\
\hline 3 & 0.594324 & 15.1007 & 0.8339 & Bandar abas \\
\hline 5 & 0.659379 & 14.3380 & 0.9789 & Shiraz \\
\hline 1 & 0.000023 & 0.0029 & 0.1606 & Zahedan \\
\hline
\end{tabular}

under assessing 49 models could gain the most efficiency grade by 40 models and in relation with other models i.e. A1, A2, A12, AB1, AB2, AB12, B1, $B 2, B 12$ are recognized as inefficient and shows that this airport could not use from the maximum input capacities like A and B. but Tabriz and Isfahan airports could not achieve maximum efficiency by At least one model and this caused them to have the least efficiency compared to the other airports.

\section{Complete ranking of the airports}

As it is said before with regard to the importance of models results, in this part it is tried that by gathering results of different models we achieve a complete ranking of our international airports. With the assumption that $\mathrm{n}$ is decision unit, that each one has $\mathrm{m}$ input and $\mathrm{s}$ output and also assume that these decision units by a set of different models of data envelopment analysis was analyzed and their efficiency grades was accounted by each of the models. By making a matrix in aspects $E_{n+k}$ which every line of this matrix shows one special decision unit and each of the columns of this matrix shows a special combination of inputs and outputs. Each of the properties of this matrix shows efficiency grade of decision unit $\mathrm{j}$-th from the point of J-th (Soleimani et al.,2009).

$\begin{array}{ccccc}M_{1} & M_{:} & \ldots & M_{K} \\ \downarrow & \downarrow & \downarrow & \downarrow \\ E_{11} & E_{1:} & \ldots & E_{1 k} \\ E_{21} & E_{2} & \ldots & E_{2 k} \\ \vdots & \vdots & & \vdots \\ E_{n 1} & E_{n} & \ldots & E_{n k}\end{array} \mid$

In fact the above matrix is a multi-index decision matrix that each line of this matrix makes an alternative and each column of this matrix makes an index for assessing that alternative. At the end for ranking the airports Vikor technique has been used as one of the most used technique for multi index deciding that the results of applying this technique has been summarized in Table 4.

As is obvious in the above table the results of complete ranking of the country's international airports shows that Zahedan international airport compared to the other airports is in the first rank and has the best activity among other international airports. On the other hand Isfahan international airport is in the last rank it means the eight ranks and has the weakest activity among other airports.

\section{Conclusion}

Today assessing the activity of airports is important because of the importance of the air transportation industry in comparison with other methods of transporting. The common methods of assessing the activity usually consider output levels resulting from activity of the organization's system, while with a systemic approach we can easily understand that reaching to the outputs is possible by making use of 
Table 4. The results of efficiency of international airports with the different models

\begin{tabular}{|c|c|c|c|c|c|c|c|c|c|c|}
\hline AB3 & AB2 & $\mathrm{AB} 1$ & A123 & A23 & A13 & A12 & A3 & A2 & $\mathrm{A} 1$ & $\begin{array}{l}\text { model } \\
\text { airport }\end{array}$ \\
\hline 1.000 & 0.402 & 0.402 & 1.000 & 1.000 & 1.000 & 0.380 & 1.000 & 0.380 & 0.373 & imam \\
\hline 0.907 & 1.000 & 1.000 & 1.000 & 1.000 & 1.000 & 1.000 & 0.880 & 1.000 & 1.000 & Mehr abad \\
\hline 0.943 & 1.000 & 1.000 & 1.000 & 1.000 & 1.000 & 1.000 & 0.943 & 1.000 & 1.000 & Mashad \\
\hline 0.738 & 0.818 & 0.818 & 0.755 & 0.745 & 0.755 & 0.755 & 0.729 & 0.745 & 0.755 & Tabriz \\
\hline 0.772 & 0.758 & 0.758 & 0.775 & 0.775 & 0.770 & 0.706 & 0.770 & 0.666 & 0.706 & Isfahan \\
\hline 0.799 & 1.000 & 1.000 & 0.868 & 0.841 & 0.868 & 0.868 & 0.774 & 0.841 & 0.868 & Bandar abas \\
\hline 1.000 & 0.971 & 0.971 & 1.000 & 1.000 & 1.000 & 0.898 & 1.000 & 0.782 & 0.898 & Shiraz \\
\hline 1.000 & 1.000 & 1.000 & 1.000 & 1.000 & 1.000 & 1.000 & 1.000 & 1.000 & 1.000 & Zahedan \\
\hline ABC23 & ABC13 & $\mathrm{ABC} 12$ & ABC3 & ABC2 & $A B C 1$ & AB123 & AB23 & AB13 & AB12 & $\begin{array}{l}\text { Model } \\
\text { airport }\end{array}$ \\
\hline 1.000 & 1.000 & 1.000 & 1.000 & 1.000 & 1.000 & 1.000 & 1.000 & 1.000 & 0.433 & imam \\
\hline 1.000 & 1.000 & 1.000 & 0.907 & 1.000 & 1.000 & 1.000 & 1.000 & 1.000 & 1.000 & Mehr abad \\
\hline 1.000 & 1.000 & 1.000 & 0.944 & 1.000 & 1.000 & 1.000 & 1.000 & 1.000 & 1.000 & Mashad \\
\hline 0.834 & 0.818 & 0.834 & 0.738 & 0.834 & 0.818 & 0.834 & 0.834 & 0.818 & 0.834 & Tabriz \\
\hline 0.797 & 0.798 & 0.758 & 0.772 & 0.724 & 0.758 & 0.798 & 0.797 & 0.798 & 0.758 & Isfahan \\
\hline 1.000 & 1.000 & 1.000 & 0.799 & 1.000 & 1.000 & 1.000 & 1.000 & 1.000 & 1.000 & Bandar abas \\
\hline 1.000 & 1.000 & 0.971 & 1.000 & 0.825 & 0.971 & 1.000 & 1.000 & 1.000 & 0.971 & Shiraz \\
\hline 1.000 & 1.000 & 1.000 & 1.000 & 1.000 & 1.000 & 1.000 & 1.000 & 1.000 & 1.000 & Zahedan \\
\hline B2 & B1 & AC123 & AC23 & AC13 & AC12 & AC3 & AC2 & AC1 & ABC123 & $\begin{array}{l}\text { Model } \\
\text { airport }\end{array}$ \\
\hline 0.386 & 0.331 & 1.000 & 1.000 & 1.000 & 1.000 & 1.000 & 1.000 & 1.000 & 1.000 & imam \\
\hline 1.000 & 1.000 & 1.000 & 1.000 & 1.000 & 1.000 & 0.880 & 1.000 & 1.000 & 1.000 & Mehr abad \\
\hline 0.807 & 0.712 & 1.000 & 1.000 & 1.000 & 1.000 & 0.944 & 1.000 & 1.000 & 1.000 & Mashad \\
\hline 0.804 & 0.772 & 0.755 & 0.745 & 0.755 & 0.755 & 0.729 & 0.745 & 0.755 & 0.834 & Tabriz \\
\hline 0.664 & 0.680 & 0.776 & 0.776 & 0.772 & 0.706 & 0.770 & 0.666 & 0.706 & 0.798 & Isfahan \\
\hline 1.000 & 1.000 & 0.868 & 0.841 & 0.868 & 0.868 & 0.774 & 0.841 & 0.868 & 1.000 & Bandar abas \\
\hline 0.718 & 0.841 & 1.000 & 1.000 & 1.000 & 0.898 & 1.000 & 0.782 & 0.898 & 1.000 & Shiraz \\
\hline 1.000 & 1.000 & 1.000 & 1.000 & 1.000 & 1.000 & 1.000 & 1.000 & 1.000 & 1.000 & Zahedan \\
\hline BC13 & BC12 & BC3 & BC2 & BC1 & B123 & B23 & B13 & B12 & B3 & $\begin{array}{l}\text { Model } \\
\text { airport }\end{array}$ \\
\hline 1.000 & 1.000 & 1.000 & 1.000 & 1.000 & 1.000 & 1.000 & 1.000 & 0.386 & 1.000 & imam \\
\hline 1.000 & 1.000 & 0.907 & 1.000 & 1.000 & 1.000 & 1.000 & 1.000 & 1.000 & 0.907 & Mehr abad \\
\hline 0.729 & 0.814 & 0.573 & 0.814 & 0.729 & 0.807 & 0.807 & 0.712 & 0.807 & 0.573 & Mashad \\
\hline 0.816 & 0.829 & 0.738 & 0.829 & 0.807 & 0.832 & 0.832 & 0.816 & 0.804 & 0.738 & Tabriz \\
\hline 0.791 & 0.699 & 0.752 & 0.679 & 0.699 & 0.791 & 0.785 & 0.791 & 0.680 & 0.752 & Isfahan \\
\hline 1.000 & 1.000 & 0.799 & 1.000 & 1.000 & 1.000 & 1.000 & 1.000 & 1.000 & 0.799 & Bandar abas \\
\hline 0.963 & 0.842 & 0.907 & 0.728 & 0.842 & 0.963 & 0.943 & 0.963 & 0.841 & 0.907 & Shiraz \\
\hline 1.000 & 1.000 & 1.000 & 1.000 & 1.000 & 1.000 & 1.000 & 1.000 & 1.000 & 1.000 & Zahedan \\
\hline \multicolumn{2}{|c|}{ C123 } & $\mathrm{C} 23$ & C13 & C12 & C3 & C2 & C1 & BC123 & BC23 & $\begin{array}{l}\text { Model } \\
\text { airport }\end{array}$ \\
\hline \multicolumn{2}{|c|}{1.000} & 1.000 & 1.000 & 1.000 & 1.000 & 1.000 & 1.000 & 1.000 & 1.000 & imam \\
\hline \multicolumn{2}{|c|}{1.000} & 1.000 & 1.000 & 1.000 & 0.515 & 1.000 & 1.000 & 1.000 & 1.000 & Mehr abad \\
\hline \multicolumn{2}{|c|}{0.561} & 0.555 & 0.561 & 0.561 & 0.543 & 0.555 & 0.561 & 0.814 & 0.814 & Mashad \\
\hline \multicolumn{2}{|c|}{0.585} & 0.585 & 0.585 & 0.585 & 0.585 & 0.585 & 0.585 & 0.832 & 0.832 & Tabriz \\
\hline \multirow{2}{*}{\multicolumn{2}{|c|}{$\begin{array}{l}0.477 \\
0.589\end{array}$}} & 0.477 & 0.477 & 0.477 & 0.477 & 0.477 & 0.477 & 0.791 & 0.785 & Isfahan \\
\hline & & 0.589 & 0.589 & 0.589 & 0.589 & 0.589 & 0.589 & 1.000 & 1.000 & Bandar abas \\
\hline \multicolumn{2}{|c|}{0.488} & 0.488 & 0.488 & 0.488 & 0.488 & 0.488 & 0.488 & 0.963 & 0.943 & Shiraz \\
\hline \multicolumn{2}{|c|}{0.988} & 0.988 & 0.988 & 0.988 & 0.988 & 0.988 & 0.988 & 1.000 & 1.000 & Zahedan \\
\hline
\end{tabular}

outputs and by using suitable processes and so fix attention to the outputs in assessing and managing the activity makes us mistake. In this research the technique of data envelopment analysis is used as an effective means for assessing decision units that have many similar inputs and outputs. But in method to increase distinguishing power between efficient and inefficient units, the number of units under assessing shall be equal with the number of input and output variables. So in this research different synthetics of inputs and outputs for cover assessing data model was used and efficiency of the airports has been accounted for different synthetics. Totally the efficiency marks from 49 different synthetics for each airport gained. The results show that the airports gained different marks in different synthetics. At the end for complete ranking of the airports the VIKOR technique was used. Such that by forming a matrix that its columns the models from different synthetic inputs and outputs and the lines showed the airports. By the use of Vikor technique complete ranking of country's airports has been gained. Results of the ranking showed that Zahedan airport has the best efficiency and Isfahan airport the worst efficiency in sum of the different synthetic inputs and outputs among our international airports in the country.

The positive point of this research in relation with other previous researches that have been done in the field of applying data envelopment analysis in the airports is considering different synthetic inputs and outputs for the airports that in case it made the airports to be compare with 
each other with different synthetics equally and also in case that the number of units under consideration in relation with the number of inputs and outputs was lower than special amount that by use of data envelopment analysis one cannot distinguish them that approach is exactly suitable. In future researches it is proposed that combining techniques of data envelopment analysis and analyzing the main elements for assessing the country airports be used. So that first in spite of the main variables, relation of one output to one input be used. Then the method of assessing the main elements on the relation of one output to one input is done and then by choosing main elements it can be analyzed and used as inputs of data envelopment analysis.

\section{References}

1. Adler Nand Berechman J (2001) Measuring airport quality from the airlines viewpoint: an application of data envelopment analysis. Transport Policy. 8, 171-181.

2. Amiri M, Ayazi A,Olfat L and Moradi J (2011)Group decision making process for supplier selection with VIKOR under fuzzy circumstance case study: An iranian car parts supplier. Int. Bulletin of Business Admin. 10, 6275.

3. Andersen $P$ and Petersen NC (1993) A procedure for ranking efficient units in DEA. Manage. Sci. 39, 12611264.

4. Bal H, Orkcu HH and Celebioglu S (2010) Improving the discrimination power and weights dispersion in the data envelopment analysis.Comput. \& Operations Res. 37, 99-107.

5. Banker RD, Charnes A and Cooper WW (1984) Some models for estimating technical and scale inefficiencies in data envelopment analysis. Manage. Sci. 30(9),10781092.

6. Barros CP and Dieke PUC (2008) Measuring the economic efficiency of airports: a Simar-Wilson methodology analysis. Transportation Res. Part E.44(6), 1039-1051.

7. BruceHo C and Dash Wu D (2009)Online banking performance evaluation using data envelopment analysis an de principal component analysis. Comput. \& Operations Res. 36,1835-1842.

8. Chang $C$ and Hsu C (2009)Multi-criteria analysis via the VIKOR method for prioritizing land-use restraint strategies in the Tseng-Wen reservoir watershed.J. Environ. Manage. 90, 3226-3230.

9. Charnes A, Cooper WW and Rhodes E (1978) Measuring the efficiency of decision-making units. Europ. J. Operational Res. 2(6), 429-444.

10. Fung MKY, Wan KKH, Hui $Y V$ and Law JS (2008)Productivity changes in Chinese airports 19952004. Transportation Res. Part E. 44(3), 521-542.

11. Gillen D and Lall A (2001). Developing measures of airport productivity and performance: an application of data envelopment analysis. Transportation Res. Part E. 33, 261-273.

12. Gillen D and Lall A (1997) Non-parametric measures of efficiency of US airports. Intl. J. Transport Econom. 28,283-306.
13. Martin JCand RománC (2007) Political opportunists and mavericks a typology of Spanish airports. Int. J. Transport Econom. 34(2),247-271.

14. Mehregan Ahmadreza (2007)Quantitative models. Management faculty, Tehran University Press.

15. Murillo-Melchor C (1999) An analysis of technical efficiency and productive change in Spanish airports using the Malmquist index. Intl. J. Transport Econom. 26,271-292.

16. Parker D (1999)The performance of the BAA before and after privatization. J. Transport Econom. \& Policy. 33, 133-146.

17. Pathomsiri S, Haghani A, Dresner Mand Windle RJ (2008) Impact of undesirable outputs on the productivity of US airports. Transp. Res. Part E Logistics \& Transp. Rev. 44,235-259.

18. Pels E, Nijkamp P and Rietveld P (2001) Relative efficiency of European airports. Transport Policy. 8,183192.

19. Roghanian E and Foroughl A(2010)An empirical study of Iranian regional airports using robust data envelopment analysis. Intl. J. Industrial Engg. Computations. 1, 65-72.

20. Samoilenko $S$ and Osei-Bryson KM (2008) Increasing the discriminatory power of DEA in the presence of the sample heterogeneity with cluster analysis and decision trees. Expert Systems with Appli. 34(2), 1568-1581.

21. Sarkis $J(2000)$. Operational efficiency of major US airports. J. Operation Managnt. 18,251-335.

22. Sarkis $J$ and Talluri $S$ (2004) Performance-based clustering for benchmarking of US airports. Transportation Res. Part A. 38,329-346.

23. Seol H, Choi J, Park G and Park Y (2007) A framework for benchmarking service process using data envelopment analysis and decision tree. Expert Sys. Appli. 32(2), 432-440.

24. Sohn Sand Moon T (2004) Decision tree based on data envelopment analysis for effective technology commercialization. Expert Sys. Appli. 26(2),279-284.

25. Soleimani-damaneh $M$ and Zarepisheh M (2009) Shannon's entropy combining the efficiency results of different DEA models: Method and application. Expert Sys. Appl. 36,5146-5150.

26. Yang $H(2010)$ Measuring the efficiencies of asia-pacific international airports: Parametric and Non-Parametric Evidence. Comput. \& Industrial Engg. pp: 697-702.

27. Yoshida Y (2004) Endogenous-weight TFP measurement: methodology and its application to Japanese-airport benchmarking. Transportation Res. Part E.40,151-182.

28. Yoshida Yand Fujimoto H (2004) Japanese-airport benchmarking with DEA and endogenous-weight TFP methods: testing the criticism of over-investment in Japanese regional airports. Transportation Res. Part E. 40, 533-546.

29. Yu MM, Hsu SH, Chang CC and Lee DH (2008) Productivity growth of Taiwan's major domestic airports in the presence of aircraft noise. Transp. Res. Part $E$ Logistics \& Transp. Rev. 44(3), 543-554. 